\title{
Editorial
}

\section{Analyzing design review conversations: Connecting design knowing, being and coaching}

Whether they occur formally or informally in academic or professional settings, design review conversations are interactive performances between those who give and those who receive feedback, advice, critique, or mentoring. They are sites of authentic practice where design coaches (i.e., instructors, peers, experts, and industry or community stakeholders) implicitly or explicitly demonstrate or perform their design knowing and being, and make their accumulated experience, knowledge, competencies, values, and belief systems visible and shareable to others. They also provide a window into the insights coaches have about design learners as they seek to support them in becoming designers. For example, during a design review coaches readily identify problematic and promising aspects of a designer's work by drawing on repertoires of practice and knowledge to anticipate problems learners may encounter and ways to help them work through these problems. They point out features of a design that could be improved, push learners to justify their ideas about 'good design' more clearly and thoroughly, and praise design work by pointing to particular insights and choices. Design learners are also performing their design knowing and being - making visible their reasoning, perspectives, and habits of mind. Through design review conversations, learners are supported in revisiting and critically evaluating their design rationales, and making sense of design review experiences in ways that allow them to construct their own design thinking repertoire and evolving design identity.

Design review conversations are robust sites for investigation and action. They offer multiple lines of inquiry into the nature and nurture of design expertise - in ways that make manifest design thinking and ways of being and becoming, reveal interactions among personal-social-epistemic dimensions, and convey disciplinary values, norms, and expectations (Adams \& Siddiqui, 2016). As a prevalent and common approach for helping designers to develop and demonstrate design expertise, they offer actionable insights that carry relevance across design domains. As such, design review conversations offer pathways for bridging the gap between design research and design practice.

The papers presented in this special edition all stem from the $10^{\text {th }}$ Design Thinking Research Symposium (DTRS) held at Purdue University, Indiana, USA, in October 2014 in which participants shared a common dataset of design review conversations. This common dataset served a three-fold, interconnected purpose. First it provided a common focus of inquiry for researchers from a diverse range of perspectives working in their own domains including art, architecture, business, cognitive and learning sciences, communication, computer science, design, education, engineering, industrial and product design, informatics and computing, science and technology, and sociology. The dataset also fostered collaborative inquiry among these researchers as they came together to share their findings at the symposium and make connections across individual studies to link aspects of design inquiry, design discourse and interactions (involving humans and 
non-humans), design being and becoming, and design coaching. Finally, through this special issue in Design Studies, the symposium proceedings

(http://docs.lib.purdue.edu/dtrs/2014/), a book based on the symposium, Analyzing Design Review Conversations and a special issue of CoDesign on the visual and material dimensions of design review interactions (forthcoming in 2016), we hope these same conversations foster community inquiry among a global cohort of design researches, educators, and professionals.

As shown in Figure 1, the DTRS10 dataset consisted of video-recordings with associated transcriptions of design review conversations across different disciplines, review structures (e.g., formal and informal, one-on-one and group critiques, in classroom, studio, and client settings), and design phases over a 3-month period (see Adams, 2016). The dataset also included work products such as digital presentations, storyboards, and prototypes. Participants in the design review conversations included students working individually and in teams on design projects and numerous versions of coaches: instructors, experts, industry and community stakeholders, and peer students. The settings included choreography, entrepreneurial design, industrial design, mechanical engineering design, and service-learning multidisciplinary design. While there were many similarities, design reviews across settings varied in their structure, intentionality, and approach. All data were collected from June 2013 to January 2014 in naturally occurring settings.

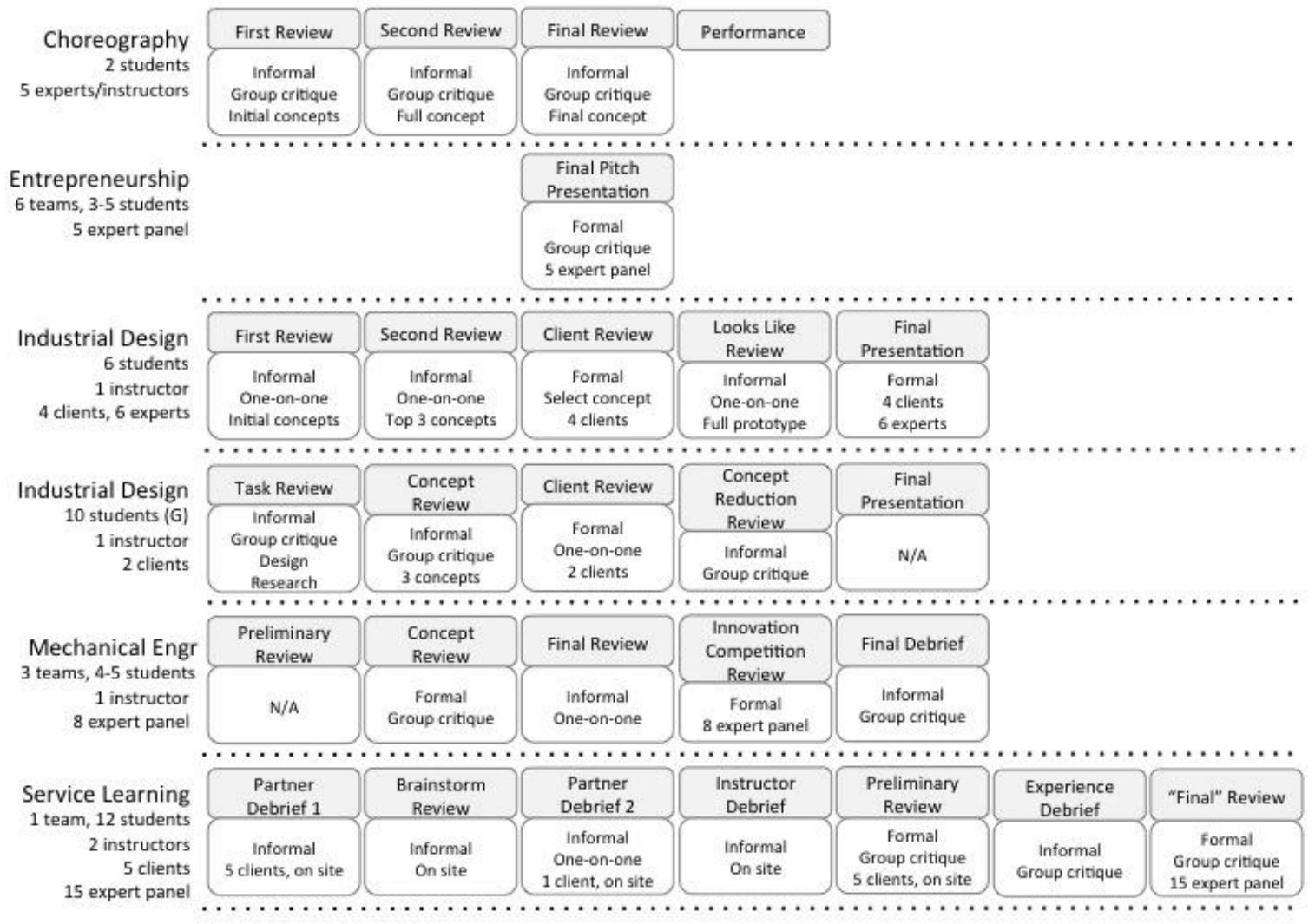

Figure 1. An overview of the DTRS 10 dataset (for more details see Adams, 2016). 
This history of sharing a common dataset to bring together diverse methodologies and advance an integrative synthesis on the nature and nurture of design expertise has become a 'landmark in design thinking research' (McDonnell \& Lloyd, 2009a). Figure 2 illustrates the expanding scale and scope of Design Thinking Research Symposia shared datasets - broadening to include multiple contexts over time, inclusive of different disciplines, and a capacity to support different theoretical and methodological frameworks. For example, DTRS2 held at TU Delft, The Netherlands, focused on the use of protocol analysis as a research tool for analyzing individual and team design activity (see Cross, Christiaans, \& Dorst, 1996; Dorst, 1995); DTRS7 held at Central Saint Martins College of Art and Design in London, UK, focused on stakeholders' design meetings in authentic settings (see McDonnell and Lloyd, 2009a; 2009b). Taking a slightly different track, DTRS9 held at the University of Northumbria, UK, was based on a shared design task - the design of products, spaces, and services for making growing old seem more attractive and inviting (Rodgers, 2012; Rodgers, 2013).

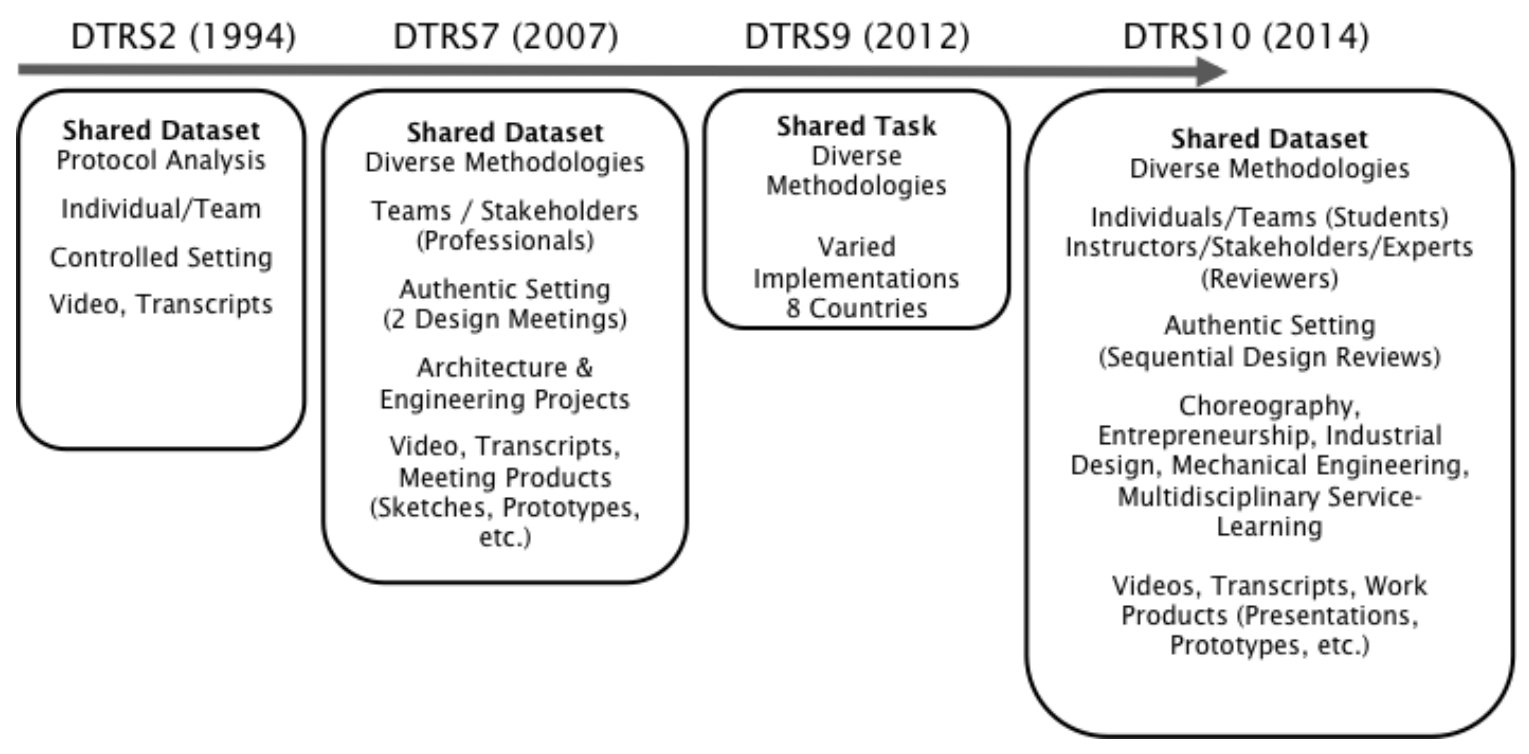

Figure 2. A historical review of shared DTRS datasets.

As a collection, the papers selected for this special issue provide vantage points for imagining a more holistic perspective that embraces the complexities of design. These papers argue for an integrative view that connects design knowing with ways of being and becoming (see Dall'Alba, 2009), and further connects these with design coaching practices. Some authors bridged or borrowed frameworks from within and outside design domains; others challenged existing views, and revealed new conceptualizations or areas of inquiry that have potential to advance our collective understanding of the nature and 
nurture of design expertise. Whether authors focused their investigations on design inquiry, design being, or design coaching, each took up the work of connecting design research to design practice. They collectively make connections between what happens within design review conversations and the ways coaches support or stimulate learners in becoming designers - pushing them to commit, justify, defend, evaluate, and reconsider their decisions with an eye towards what it means to be a designer. From this vantage point, they offer a variety of recommendations regarding the critical role of coaching in design and the importance of reflecting on coaching practices.

In 'Scaffolding practices: A study of design practitioner engagement in design education', McDonnell provides further insights into the ways that students acquire design expertise through interactions with a design educator. McDonnell accomplishes this by examining the activities of the design educator as well as examining the design work itself as a rhetorical instrument that facilitates the student's own process of thinking through a design as well as the conversation between the student and the educator. This exploration of the design work itself as a rhetorical instrument introduces a new actor into the design review conversations. Beyond this, McDonnell discusses the activities of the design educator both during the design review conversations and during other aspects of the design course. While some papers in this issue focus on the design review conversations exclusively, McDonnell provides us with a glimpse into the direction the educator provides when she initially prescribes a design process, as she assigns a set of design activities for the students to complete. By recognizing the initial prescribed design process, McDonnell is also able to make visible the shifts the educator makes to later allow the students to develop their own values, preferences and design sensibilities. The design work provides a space for the student to think, design and reflect - and then becomes the avenue for the student to present their ideas to the educator for feedback.

Students benefit from the advice of external advisors - coaches (who may be educators, clients, classmates, or others) who provide personalized feedback focused on concepts, skills and the specific work at hand. In 'Characterizing the work of coaching during design reviews', Adams, Forin, Chua and Radcliffe draw on work from the learning sciences community to help us conceptualize the work of coaching as design 'pedagogical content knowledge' (PCK), where knowledge of design, knowledge of students, and knowledge of teaching are intertwined. Further, Adams and her colleagues use learning sciences frameworks to present the work of coaching as integrated knowing, situated practice, and shared repertoires of practice. This discussion also helps us understand the work of coaching as a process mirroring design, where the coaches draw on their own design expertise as they enact design PCK. Looking across three undergraduate design contexts (choreography, industrial design, and mechanical engineering) they identify four patterns of coaching: scaffolding articulation, driving for meaning and guidance, breaking the 4th wall to create a teaching moment, and using a 'suggest don't tell' approach to feedback to allow the feedback recipient to figure out how to make improvements. The authors offer connections to other work, exploring: ways of characterizing design judgment (Christensen and Ball; Wolmarans); generative sensing (Dong et al.) as complementary to the 'suggest don't tell' approach; patterns of how coaches embody and enact their integrated knowledge of design and knowledge of 
students as design learners (McDonnell); and ways coaches drive the complexity within design reviews (Yilmaz and Daly).

In 'Generative sensing in design evaluation', Dong, Garbuio and Lovallo challenge existing perspectives on design reasoning during concept design evaluation to make evident a new pattern called generative sensing. Borrowing from the scholarship of strategic decision-making, the authors argue that known patterns of design thinking do not fully capture the kinds of reasoning that may occur during concept evaluations. They investigated how and if concept evaluation within a design review is strictly convergent and if it should be characterized by deductive reasoning alone. Two contrasting contexts from the dataset (entrepreneurial design final proposal reviews and industrial design concept reviews) were selected to make spontaneous deductive and abductive reasoning observable. They found that the critique and assessment of 'not-yet-fully-elaborated' concepts in relation to their suitability to a design brief is neither strictly deductive or abductive, but a distinctive new pattern of reasoning combining the two. This new pattern of generative sensing is a recursive hypothesis-driven process of deductive reasoning occurring in conjunction with abductive reasoning. The authors offer connections between generative sensing and other studies in this issue in terms of instructors using critiques as rhetorical devices to help students take a position about their design ideas (McDonnell), challenging a student's commitment to a design decision without prescribing actions (Adams et al.), encouraging students to be responsible for selecting the knowledge needed to respond to a design brief (Wolmarans), and inviting rebuttals to the logic of a concept (Yilmaz and Daly). They also explore how generative reasoning may rely on mental simulation skills necessary for developing design judgment (Christensen and Ball).

In 'Inferential reasoning in design: Relations between material product and specialised disciplinary knowledge', Wolmarans investigates the nature of inferential reasoning in mechanical engineering design reviews. In particular, she uses the Semantics dimension of Legitimation Code Theory to characterize interactions between semantic density and semantic gravity as students work with multiple disciplinary traditions (semantic density) while simultaneously moving between abstract theoretical knowledge and the material context of its application (semantic gravity). Study findings highlight the relationship between students' explanations of design performance and their experiences with the success or failure of a design, and the role of coach scaffolding in helping students elaborate or justify observations of performance (or lack of performance) in terms of the underlying theoretical underpinnings. Based on these findings, Wolmarans urges educators to align practices, course objectives, and approaches with helping students develop fluency in making interdisciplinary connections among abstract disciplinary knowledge and moving between abstract and concrete ways of thinking and reasoning. She connects her findings to other studies in this issue as an alternative view on tracing the use of specialized disciplinary knowledge that forms the basis of reasoning (Adams et al.) and the balance between a command of technical matters and the norms of practice as students are supported in developing their own design sensibilities (McDonnell). Wolmarans also makes connections between inferential reasoning as it relates to disciplinary knowledge and evaluative logic as it relates to creative judgments (Christensen \& Ball) as well as the ways instructors influence shifts in the nature of 
reasoning as cycles of abduction and deduction (Dong et al.) and convergence and divergence (Yilmaz \& Daly).

In 'Dimensions of creative evaluation: Distinct design and reasoning strategies for aesthetic, functional and originality judgments', Christensen and Ball take a novel integrative approach to investigate three types of design judgment, their underpinning logics, and how multiple logics simultaneously operate and impact reasoning strategies and suggestions in distinct and predictable ways. Three types of creative evaluation originality, functionality, and aesthetics - were investigated in two different industrial design critique settings, one involving industrial design supervisors with undergraduate students and the other with graduate students. They identified prevalent relationships along three creativity dimensions between supervisor suggestions and student reasoning strategies. They find that go/kill decisions and suggestions for information gathering were associated with originality judgments. However, functionality judgments often involved supervisor suggestions for mental simulation, changing form, and re-evaluating function. Finally, trial/error suggestions were related to aesthetic judgments. Their work highlights how creative design requires diverse skills and the critical role supervisors play in confronting students with all types of evaluative judgment. Christensen and Ball draw connections between their findings and other papers in this special issue such as understanding connections between creative evaluation with divergent and convergent thinking (Dong et al.), and highlighting the learning opportunities embedded in evaluative judgments and how they can support students in developing their own design values and sensibilities (Adams et al.; McDonnell). Similar to Yilmaz and Daly, they reiterate the importance of instructors reflecting on the consequences of their critical appraisals of student design creativity, and urge design educators and design evaluators to pay attention to the importance of feedback in relation to all three dimensions of creative evaluation.

In 'Feedback in concept development: Comparing design disciplines', Yilmaz and Daly advance research on a fundamental practice for helping novices become designers: instructor feedback in design reviews. They investigate how instructors prompt shifts in students' divergent and convergent design thinking as students create, develop, and refine ideas. By analyzing feedback provided in dance choreography, industrial design, and mechanical engineering contexts they reveal commonalities and distinguishing features of instructor feedback. Observations of feedback that prompted students towards divergent thinking focused on encouraging students to create choices for themselves such as offering alternatives; feedback that prompted students towards convergent thinking focused on asking students to make choices such as justifying ideas and managing time to minimize risk. Feedback that was neither convergent nor divergent involved directing students to elaborate or iterate on ideas for which decisions were not yet made. Across contexts, prompting convergent thinking was prevalent; there was some evidence of prompting divergent thinking but only in choreography and industrial design. Differences in feedback patterns were related to the structure and goals of review sessions. Based on their observations, Yilmaz and Daly emphasize the importance of instructors sharing coaching strategies and reflecting purposefully on the feedback they give and how it could support or hinder ideation pathways. This study offers an 
alternative vantage point for papers regarding creative design judgment (Christensen and Ball), interactions between divergent and convergent thinking (Dong et al.), and the ways design instructors encourage students to find their own design voice (Adams et al., McDonnell).

We posit that viewing design review conversations from these diverse, intersecting perspectives opens up new possibilities for imagining a holistic approach that embraces the complexities of design and offers a broad language for making connections across design inquiry, design being, and design coaching practice. We urge others to join the ongoing call for creating a working synthesis of the nature and nurture of design expertise (see Cross, 2010) and the nature and nurture of design learning that can guide theoretical and practical advancements.

\section{Acknowledgements}

DTRS 10 was funded by a Purdue Global Engineering Program International and Global Impact grant, the School of Engineering Education, Dean Leah Jamieson of the College of Engineering, and a National Science Foundation CAREER grant exploring crossdisciplinary approaches to thinking and learning (EEP- 0748005). The design of the event including the shared dataset was a Purdue University cross- institutional collaboration with faculty from the College of Engineering, the College of Liberal Arts, the Libraries; the School of Engineering Education, the School of Communication, Visual and Performing Arts, the School of Mechanical Engineering; and a certificate program in entrepreneurship and innovation. We are grateful to the various reviewers who commented on and helped to improve the papers.

Robin S. Adams, Monica Cardella, Şenay Purzer

Purdue University, School of Engineering Education

Corresponding author: Robin Adams

rsadams@purdue.edu

\section{References}

Adams, R.S. (2016). Design Review Conversations: The Dataset. In R.S. Adams \& J. Siddiqui (eds), Analyzing Design Review Conversations (Chapter 2, pp. 23-30). West Lafayette, IN: Purdue University Press.

Adams, R.S. (2016). "Inquiry into Design Review Conversations." In R.S. Adams \& J. Siddiqui (eds), Analyzing Design Review Conversations (Chapter 1, pp. 3-22). West Lafayette, IN: Purdue University Press.

Adams, R.S. \& J. Siddiqui (Eds.) (2016). Analyzing Design Review Conversations. West Lafayette, IN: Purdue University Press. 
Adams, R.S., McMullen, S., \& Fosmire, M. (Eds.) (to appear, 2016). Co-Designing Review Conversations - Visual and Material Dimensions. Special Issue of CoDesign. [This is in pre-print, but I don't know the volume, issue, page numbers]

Cross, N. (2010). Book Review: Design Expertise. Design Studies, 31, pp. 203-205.

Cross, N., Christiaans, H., \& Dorst, K. (Eds.). (1996). Analysing design activity. Chichester, UK: John Wiley.

Dall'Alba, G. (2009). Learning to be Professionals. Dordrecht: Springer.

Dorst, K. (1995). "Analysing design activity: new directions in protocol analysis." Design Studies 16, pp. 139-142.

McDonnell, J., \& P. Lloyd, P. (Eds.). (2009a). About: designing-Analysing design meetings. London: Taylor \& Francis.

McDonnell, J., \& P. Lloyd, P. (Eds.). (2009b). Analysing design conversations. Special issue of CoDesign, 5(1), pp. 1-4.

Oh, Y., Ishizaki, S., Gross, M. D., \& Do, E. Y. (2012). A theoretical framework of design critiquing in architecture studios. Design Studies 34(3), 302-325.

Rodgers, P. (Ed.). (2012). Articulating Design Thinking. Farringdon, UK: Libri Publishing.

Rodgers, P. (Ed.). (2013). Articulating design thinking. Special Issue of Design Studies, 34(4), pp. 433-437. 